Artigo

\title{
AÇÕES PEDAGÓGICAS REALIZADAS COM OS ESTUDANTES SURDOS EM SALAS DE AEE NA PERSPECTIVA DA EDUCAÇÃO INCLUSIVA
}

\author{
PEDAGOGICAL ACTIONS CARRIED OUT WITH DEAF STUDENTS IN AEE ROOMS \\ FROM THE PERSPECTIVE OF INCLUSIVE EDUCATION

\begin{abstract}
ACCIONES PEDAGÓGICAS REALIZADAS CON ESTUDIANTES SORDOS EN
\end{abstract} \\ HABITACIONES AEE DESDE LA PERSPECTIVA DE LA EDUCACIÓN INCLUSIVA
}

\author{
Luciana Costa Souza \\ Claudia Braga Maia
}

\begin{abstract}
Resumo
O presente artigo tem como objetivo principal analisar as ações pedagógicas realizadas com os estudantes surdos em salas de AEE, tendo por base as diretrizes da Política Nacional da Educação Especial na Perspectiva da Educação Inclusiva PNEEI, além de fundamentar-se nas ideias de Damázio (2007) e Quadros (2006). Além disso, busca também destacar a relevância do atendimento educacional especializado. A investigação de abordagem qualitativa constitui-se num estudo de caso que utilizou como instrumentos de coleta de dados a pesquisa bibliográfica e a análise documental. $O$ estudo verificou em uma sala de AEE, no município de Feira de Santana, que o trabalho pedagógico realizado com estudantes surdos é voltado ao ensino da Libras e da Língua Portuguesa, visando diminuir as dificuldades na aprendizagem escolar apresentadas pelos alunos atendidos no AEE. A análise dos planos de aula, atividades e documentos norteadores do trabalho pedagógico realizado pelo docente pesquisado permitiram ver a importância do AEE como complemento ao trabalho realizado no ensino regular que ainda mostra-se, muitas vezes, despreparado para receber o aluno surdo.
\end{abstract}

\begin{abstract}
The main objective of this article is to analyze the pedagogical actions carried out with deaf students in ESA rooms, based on the guidelines of the National Policy for Special Education from the perspective of Inclusive Education - PNEEI, in addition to being based on the ideas of Damázio ( 2007) and Quadros (2006). In addition, it also seeks to highlight the relevance of specialized educational assistance. The investigation with a qualitative approach is a case study that used bibliographic research and documentary analysis as instruments of data collection. The study found in an ESA room, in the municipality of Feira de Santana, that the pedagogical work carried out with deaf students is aimed at teaching Libras and the Portuguese language, in order to reduce the difficulties in school learning presented by the students assisted in the ESA. The analysis of the lesson plans, activities and guiding documents of the pedagogical work carried out by the researched teacher allowed us to see the importance of ESA as a complement to the work carried out in regular education, which is still often unprepared to receive the deaf student.
\end{abstract}

\section{Resumen}

El objetivo principal de este artículo es analizar las acciones pedagógicas llevadas a cabo con estudiantes sordos en las salas de la ESA, con base en los lineamientos de 
la Política Nacional de Educación Especial desde la perspectiva de la Educación Inclusiva - PNEEI, además de basarse en las ideas de Damázio ( 2007) y Quadros (2006). Además, también busca resaltar la relevancia de la asistencia educativa especializada. La investigación de un enfoque cualitativo es un estudio de caso que utilizó la investigación bibliográfica y el análisis de documentos como instrumentos de recolección de datos. El estudio encontró en una sala de la ESA, en el municipio de Feira de Santana, que el trabajo pedagógico realizado con estudiantes sordos tiene como objetivo enseñar Libras y el idioma portugués, con el fin de reducir las dificultades en el aprendizaje escolar presentado por los estudiantes asistidos en la ESA. El análisis de los planes de lecciones, actividades y documentos guía del trabajo pedagógico realizado por el profesor investigado nos permitió ver la importancia de la ESA como complemento del trabajo realizado en la educación regular, que a menudo todavía no está preparada para recibir al estudiante sordo.

Palavras-chave: Atendimento educacional especializado; Surdos; Ações pedagógicas.

Keywords: Specialized educational assistance; Deaf; Pedagogical actions.

Palabras claves: Asistencia educativa especializada; Sordo; Acciones pedagógicas.

\section{INTRODUÇÃO}

Na área da Educação, falar sobre surdez ainda suscita preocupações, isto porque a deficiência não é bem compreendida por muitos e confundida com incapacidade. A surdez é na verdade uma especificidade linguística, já que o modo de aprendizagem e comunicação do surdo é visual e não auditivo. Além disso, a primeira língua do surdo é a LIBRAS, o que ocasiona problemas na comunicação com os sujeitos a sua volta que desconhecem essa língua e tentam impor o uso da língua portuguesa, como primeira língua, numa tentativa de adequá-lo ao mundo ouvinte. Isso acontece não só na família e na sociedade de modo geral, como também na escola, pois muitos profissionais da educação ainda estão despreparados para lidar com as especificidades dos seus alunos.

Tratando mais especificamente da escola, o desconhecimento do que é a surdez de fato e os problemas de comunicação entre surdos e ouvintes causados pelo desconhecimento da libras tem ocasionado graves problemas na trajetória escolar do aluno surdo, que passa anos tentando se adaptar a uma escola, por vezes dita inclusiva, mas que não possui intérprete, com professores que desconhecem a libras, assim como colegas e funcionários da escola que não conseguem se comunicar de maneira eficaz por não conhecerem a sua língua, o que acarreta baixa autoestima, sentimento de incapacidade, isolamento e déficit na aprendizagem dos conteúdos. Essa infelizmente é a realidade da grande maioria das escolas regulares. Sobre as dificuldades enfrentadas pelos surdos Damázio (2007) afirma que:

As pessoas com surdez enfrentam inúmeros entraves para participar da educação escolar, decorrentes da perda da audição e da forma como se estruturam as propostas educacionais das escolas. Muitos alunos com surdez podem ser prejudicados pela falta de estímulos adequados ao seu potencial cognitivo, sócio-afetivo linguístico e político-cultural, e ter perdas consideráveis no desenvolvimento da 
aprendizagem. (DAMÁZIO, 2007, p.13)

Devido aos muitos entraves vividos pelo aluno com surdez, este se vê diante da necessidade de buscar apoio em outra instituição, que realize o atendimento educacional especializado (AEE). $O$ que seria 0 atendimento educacional especializado? Conforme o Decreto $\mathrm{n}^{-}$7.611/2011 um dos objetivos do atendimento educacional especializado é "prover condições de acesso, participação e aprendizagem no ensino regular e garantir serviços de apoio especializados de acordo com as necessidades individuais dos estudantes". Complementando esta ideia, as Diretrizes da Política Nacional da Educação Especial na perspectiva da Educação Inclusiva trazem que:

O Atendimento Educacional Especializado (AEE) identifica, organiza e elabora recursos pedagógicos e de acessibilidade que eliminem as barreiras para a plena participação dos alunos, considerando as suas necessidades específicas. As atividades desenvolvidas no AEE diferenciam-se daquelas realizadas na sala de aula comum, não sendo substitutivas à escolarização. Este atendimento complementa e/ou suplementa a formação dos alunos com vistas à autonomia e independência na escola e fora dela". (BRASIL, 2008, p.11)

Dentre as instituições que realizam o AEE estão os Centros de Apoio Pedagógico (CAP), que atendem estudantes com deficiência, transtornos como o Transtorno do Espectro Autista ou Transtorno Global de desenvolvimento, com altas habilidades ou com dificuldades de aprendizagem, como dislexia e TDAH, matriculados na rede estadual de ensino. A missão do CAP é contribuir para a inclusão destes estudantes na escola regular, auxiliando na construção da autonomia, ampliando sua participação e interação em todas as atividades escolares, além de garantir seu aprendizado. Este trabalho será realizado no CAP do município de Feira de Santana.

A pesquisa tem como problema norteador a seguinte questão: Quais são as ações pedagógicas realizadas com estudantes surdos em salas de AEE pautadas na diretrizes da Política Nacional da Educação Especial na perspectiva da Educação Inclusiva?

A escolha deste tema surgiu ao longo do curso de Pós-graduação em LIBRAS, no qual estou em fase de conclusão, onde refleti sobre as dificuldades do surdo na escola regular vindo, então, a pensar em pesquisar o atendimento recebido por este aluno surdo numa Instituição especializada. Devido ao fato de eu já conhecer o CAP de Feira de Santana há algum tempo, tendo feito alguns cursos neste Centro, e saber que é uma instituição com boas referências e profissionais qualificados para 0 atendimento a pessoas com deficiência, eu a escolhi para ser meu lócus de pesquisa, sendo uma referência quando se trata de $A E E$..

Este trabalho está fundamentado nas ideias de Damázio (2007) que fala sobre a atendimento especializado para surdos, no Decreto 7.611/2011 que dispõe sobre a educação especial e 0 atendimento educacional especializado e na Política Nacional da Educação Especial na perspectiva da Educação Inclusiva 
A pesquisa é de abordagem qualitativa, pois busca conhecer e compreender as ações pedagógicas dos professores do CAP que realizam o Atendimento Educacional Especializado ao estudante surdo. Para Minayo (2001, apud Silveira e Córdova, 2009, p.31):

A pesquisa qualitativa trabalha com o universo de
significados, motivos, aspirações, crenças, valores e atitudes,
o que corresponde a um espaço mais profundo das relações,
dos processos e dos fenômenos que não podem ser
reduzidos à operacionalização de variáveis". (MINAYO, 2001)

O método de pesquisa desta investigação foi o estudo de caso, que segundo Fonseca (2002, apud Silveira e Córdova, 2009, p.39), é o estudo de uma entidade bem definida, como uma instituição, uma pessoa ou um sistema educativo. Além disso, ele diz que neste tipo de pesquisa o pesquisador não visa interferir sobre o seu objeto de estudo. Para responder às questões propostas para a investigação, foi feita análise bibliográfica de autores referências sobre a temática, análise documental dos materiais didáticos e documentos norteadores do trabalho pedagógico no CAP, análise de planos e aula e planos de ensino da professora pesquisada. Vale destacar que na Instituição escolhida como lócus da pesquisa há somente uma professora que trabalha com os alunos surdos, sendo assim o seu trabalho o foco desta pesquisa. A análise documental e dos planos de aula e ensino forneceram informações importantes, como em que se fundamenta o trabalho realizado, quais as diretrizes, as teorias e autores que embasam as propostas pedagógicas, além de dar uma clareza quanto às atividades que são realizadas na prática, e quais são os materiais didáticos utilizados durante os atendimentos. Esse contato com os materiais foi importante, pois poderá auxiliar professores, estudantes e outros interessados que atuam na educação de surdos, enriquecendo o leque de possibilidades de trabalho, através das ideias de atividades aqui exploradas, com o estudante surdo na sala de aula regular ou especial.

\section{O AEE: SEGUNDO A PNEEI E OUTRAS REFERÊNCIAS}

Há várias teses e dissertações produzidas no Brasil a respeito do Atendimento Educacional especializado, estabelecendo relação deste com o uso de tecnologias, com a escola regular, com a Política de Educação Especial e algumas produções ligadas ao aluno surdo.

$\mathrm{Na}$ Biblioteca Digital Brasileira de Teses e Dissertações - BDTD, pude encontrar alguns trabalhos em que a temática se relaciona em algum ponto com o tema escolhido para minha pesquisa. Envolvem a prática pedagógica com o aluno surdo ou mais especificamente 0 atendimento educacional especializado com este aluno.

Dentre os trabalhos encontrados: "Prática Pedagógica inclusiva: um estudo de caso em escola com atendimento educacional especializado (AEE) em Jaboatão dos Guararapes-PE", de Ednea Rodrigues de Albuquerque (2014), revelou que na prática "inclusiva", prevalecem experiências eternizadas no modelo tradicional da Educação Especial: perspectiva médica da deficiência, que impõe uma condição estática ao sujeito e à sua família; 
uma psicologia psicométrica, baseada no modelo classificatório e binário; e uma pedagogia terapêutica, cujo esforço se concentra na identificação das faltas contidas na deficiência, por conseguinte, subjazem os elementos contidos na trajetória de escolarização. Verificou-se, ainda, que as práticas desenvolvidas no AEE são burocratizadas, solitárias e improvisadas.

Tendo como fonte de pesquisa o Google Acadêmico, destaco o trabalho "O "Especial" na educação, o atendimento especializado e a educação especial", de Mônica Kassar e Andressa Rabelo (2011) que se propôs a conhecer a constituição do "atendimento especializado" no Brasil, mostrando como este foi se modificando ao longo da história tendo por base os documentos legais brasileiros. O texto coloca que inicialmente a atenção às pessoas com deficiência baseava-se em um discurso médico, mas nos últimos dez anos, no entanto, a política proposta pelo Governo Federal começa a desconsiderar a possibilidade de oferecimento escolar fora do sistema comum de ensino, o que fica legalmente evidente no Decreto $n^{\circ}$ 6.571/2008 e na Resolução no 04 de 2009, que admitem a realização de atendimento educacional especializado apenas complementarmente ou de forma suplementar e não mais substitutiva. Nessa perspectiva, as instituições especializadas devem se organizar como centros de atendimento educacional especializado oferecendo ações complementares ou suplementares aos espaços escolares regulares.

Por fim, cito o estudo de Ferreira (2011), que traz reflexões sobre a educação especial, a formação escolar de alunos com surdez, o seu desenvolvimento na comunicação e o atendimento educacional especializado nos três momentos didático-pedagógicos. A autora aborda a Educação Especial, na perspectiva inclusiva, como serviço complementar do Atendimento Educacional Especializado na escola/classe comum, que oferece novas possibilidades para as pessoas com surdez, em que a Libras e a Língua Portuguesa escrita são línguas de comunicação e instrução, a sala de aula e a sala de recursos multifuncionais são locais que promovem a interação e o desenvolvimento acadêmico do aluno.

Além das pesquisas já realizadas, fundamentei esta investigação nas ideias de alguns autores importantes que também tratam do Atendimento Educacional Especializado ao estudante surdo e em alguns dispositivos legais que regulamentam a Educação Especial.

Santos e Santana (2019) colocam que o AEE, de oferecimento obrigatório, deve funcionar em espaço próprio na escola, em horário oposto ao do ensino regular do aluno e deve trabalhar a Libras, o português como segunda língua e o acesso ao conhecimento científico através de estratégias metodológicas. Segundo estes autores:

A proposta de ensino-aprendizagem para o aluno surdo precisa ser na modalidade bilíngue, assim como afirma a Lei 10.436 a Libras como primeira língua da comunidade surda e a segunda língua a língua oficial do país na modalidade escrita. (SANTOS e SANTANA, 2019, p. 174)

Damázio (2007), traz algumas questões importantes sobre o Atendimento Educacional Especializado. Ela coloca que, dentre outras coisas, o ambiente educacional bilíngüe é importante e indispensável, já que respeita 
a estrutura da Libras e da Língua Portuguesa. Diz ainda que o uso de Libras ensina e enriquece os conteúdos curriculares promovendo a aprendizagem dos alunos com surdez na turma comum. Traz que os recursos visuais facilitam a compreensão do conteúdo curricular em Libras e este oferece ao aluno com surdez segurança e motivação para aprender, sendo, portanto, de extrema importância para a inclusão do aluno na classe comum.

Quanto ao Atendimento Educacional Especializado para aprendizagem da Língua Portuguesa ela afirma que o profissional deve conhecer muito bem a organização e a estrutura dessa Língua, bem como metodologias de ensino desta. $E$ para sua aquisição é preciso que o professor estimule permanentemente 0 aluno, provocando-o a enfrentar desafios. $O$ autor destaca que o atendimento em Língua Portuguesa é de extrema importância para o desenvolvimento e a aprendizagem do aluno com surdez na sala comum.

Segundo esta autora, as práticas pedagógicas são o maior problema na escolarização das pessoas com surdez, sendo necessário repensá-las para que os surdos não pensem que suas dificuldades no domínio da leitura e da escrita são advindas somente das limitações da surdez, mas principalmente das metodologias adotadas pelos professores.

A citada autora sempre se refere ao atendimento especializado na escola comum e não em escolas especiais, enfatizando o ensino bilíngue, da libras e da Língua Portuguesa. Assim surgem algumas questões, como por exemplo, qual seria então a relevância do Atendimento Educacional Especializado fora da classe comum? A Política Nacional da Educação Especial na Perspectiva da Educação Inclusiva diz que:

Ao longo de todo o processo de escolarização esse atendimento deve estar articulado com a proposta pedagógica do ensino comum. O atendimento educacional especializado é acompanhado por meio de instrumentos que possibilitem monitoramento e avaliação da oferta realizada nas escolas da rede pública e nos centros de atendimento educacional especializados públicos ou conveniados. (BRASIL, 2008, p.11 e 12).

Esta política deixa claro que o AEE deve complementar o trabalho realizado na escola regular, buscando articulação com o trabalho da classe comum.

E quem é o público atendido pelo AEE? Segundo Brasil (2008), a educação especial tem como público-alvo os alunos com deficiência, transtornos globais de desenvolvimento e altas habilidades/superdotação. Os surdos estão entre os que tem deficiência, pois apresentam impedimentos de longo prazo, de natureza sensorial, que em interação com diversas barreiras podem ter restringida sua participação plena e efetiva na escola e na sociedade. Esta definição de deficiência está presente na Política de Educação Especial.

Com relação aos profissionais que atuam no AEE, este documento traz que:

O atendimento educacional especializado é realizado mediante a atuação de profissionais com conhecimentos específicos no ensino da Língua Brasileira de Sinais, da 
Língua Portuguesa na modalidade escrita como segunda língua, do sistema Braille, do soroban, da orientação e mobilidade, das atividades de vida autônoma, da comunicação alternativa, do desenvolvimento dos processos mentais superiores, dos programas de enriquecimento curricular, da adequação e produção de materiais didáticos e pedagógicos, da utilização de recursos ópticos e não ópticos, da tecnologia assistiva e outros. (BRASIL, 2008, p.17)

Algo importante a ser destacado no texto da Política é que segundo suas diretrizes, o atendimento educacional especializado é ofertado, tanto na modalidade oral e escrita, quanto na língua de sinais. E orienta que na medida do possível, o aluno surdo deve estar com outros pares surdos em turmas comuns na escola regular.

Complementando tais ideias, o Decreto ํo 7.611/2011 em seu artigo $2^{\circ}$, parágrafo segundo, coloca que:

O atendimento educacional especializado deve integrar a proposta pedagógica da escola, envolver a participação da família para garantir pleno acesso e participação dos estudantes, atender às necessidades específicas das pessoas público-alvo da educação especial, e ser realizado em articulação com as demais políticas públicas. (BRASIL, 2011, p. 1).

$O$ referido decreto apresenta alguns dos objetivos do AEE: Prover condições de acesso, participação e aprendizagem no ensino regular e garantir serviços de apoio especializados de acordo com as necessidades individuais dos estudantes; e fomentar o desenvolvimento de recursos didáticos e pedagógicos que eliminem as barreiras no processo de ensino e aprendizagem.

Desta forma, as ideias aqui apresentadas a respeito do Atendimento Educacional Especializado embasaram este trabalho de investigação, servindo como referência para a análise do trabalho realizado na Instituição escolhida como lócus de pesquisa.

\section{RESULTADOS E DISCUSSÃO}

A pesquisa foi feita em uma sala de $A E E$, tendo em vista que na Instituição escolhida para estudo havia somente uma docente atuando com os estudantes surdos. Antes de ter acesso ao material utilizado pela professora em suas aulas, tivemos uma conversa informal que trouxe alguns esclarecimentos para melhor contextualizar o trabalho.

A professora que realiza 0 atendimento educacional especializado é surda, formada em Letras, Especialista em Libras e graduanda do curso de Licenciatura em Língua Brasileira de Sinais, o que mostra que possui uma excelente formação. A Política de Educação Especial na Perspectiva da Educação Inclusiva coloca que o profissional que atua no ensino a estudantes surdos deve ter um conhecimento especializado da libras. Com relação a isso, pode-se notar que a professora pesquisada, por ser surda, alfabetizada nas 
duas línguas, com formação na área está bem preparada para a docência no AEE.

Em conversa informal, a professora informou que atualmente o CAP possui 10 alunos surdos em atendimento, com idades que variam entre 8 e 35 anos. Estes muitas vezes relatam suas dificuldades na escola regular, pois não tem nenhum tipo de atendimento especializado voltado para eles. Alguns alunos chegam ao AEE sem saber escrever o próprio nome. A professora ensina Libras e Língua Portuguesa.

Para seu planejamento a professora utiliza como referencial o livro de Quadros (2006), chamado "Ideias para ensinar português para alunos surdos", que além de contextualizar a educação bilíngue, traz várias propostas de atividades. Dentre as ideias expressas no livro, ela diz que para que o aluno surdo possa se tonar um leitor em Língua Portuguesa, é preciso se tornar leitor na Língua de sinais. Então, apresenta algumas formas de explorar essa língua no processo de alfabetização: configuração de mãos, movimentos, expressões faciais gramaticais, espaço de sinalização, dentre outras.

As estórias e a literatura são indicadas pela autora como facilitadoras no processo de aprendizagem da língua. Outra ação que deve estar envolvida no trabalho pedagógico é ler sinais. A autora elenca alguns objetivos a serem trabalhados pelo professor, são eles: desenvolver o uso de estratégias específicas para resolução de problemas; exercitar o uso de jogos de inferência; trabalhar com associações; desenvolver as habilidades de discriminação visual; explorar a comunicação espontânea; ampliar constantemente vocabulário; oferecer constantemente literatura impressa na escrita em sinais; proporcionar atividades para envolver a criança no processo de alfabetização como autora do próprio processo.

O livro traz que, para ensinar português o professor deve ser um especialista na Língua de Sinais, pois o surdo só conseguirá aprender a segunda língua quando já tiver domínio da primeira. Vale ressaltar que a docente do AEE também é surda, podendo não só ensinar a libras e o português para os alunos como também compreender muito bem o que seu aluno vivencia e auxiliá-lo na superação das dificuldades. Muitas vezes, a criança surda não tem contato com outros surdos e por isso não aprende libras nem em casa, nem na escola, o que dificulta o seu aprendizado. Como nos foi relatado pela professora do CAP, ela recebe crianças e adultos que não aprenderam ainda a libras e é preciso fazer um trabalho pedagógico para o aprendizado das duas línguas, a libras e o português.

Ainda seguindo as ideias de Quadros (2006) ao se trabalhar a leitura, o professor precisa conversar com seu aluno surdo sobre o texto, fazê-lo compreender e para isso é importante escolher textos variados, adequados à faixa etária e que motivem o seu aluno.

Quadros (2006), utilizado como referencial pela professora no AEE, traz muitas atividades e ideias interessantes que podem ser notadas nas atividades desenvolvidas no CAP. Por exemplo, a utilização de alfabeto manual (em libras), fichas com palavras em português, atividades para completar frases escritas a partir de imagens ou textos, discussão em libras sobre determinado tema trabalhado e escrita de palavras relacionadas ao texto ou tema, criar uma frase ou diálogo a partir de imagens ou palavras já trabalhadas anteriormente e muitas propostas lúdicas, como se pode ver nas 
figuras 1, 2, 3 e 4, abaixo.

Figura 1 (Jogo de memória):
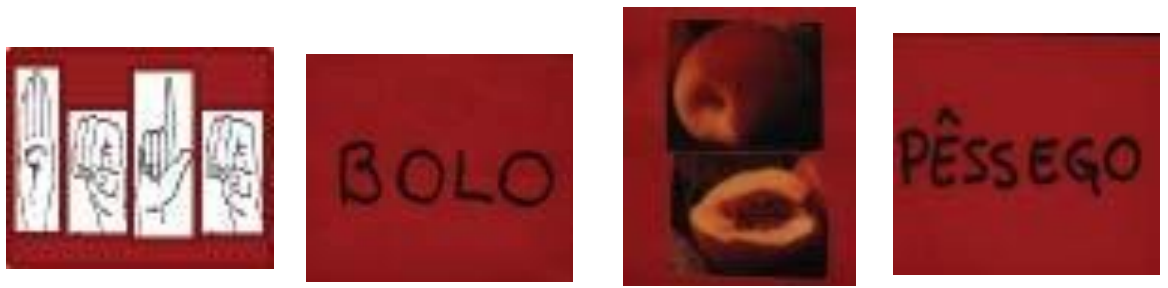

Figura 2 (Produção a partir de roteiros dados):

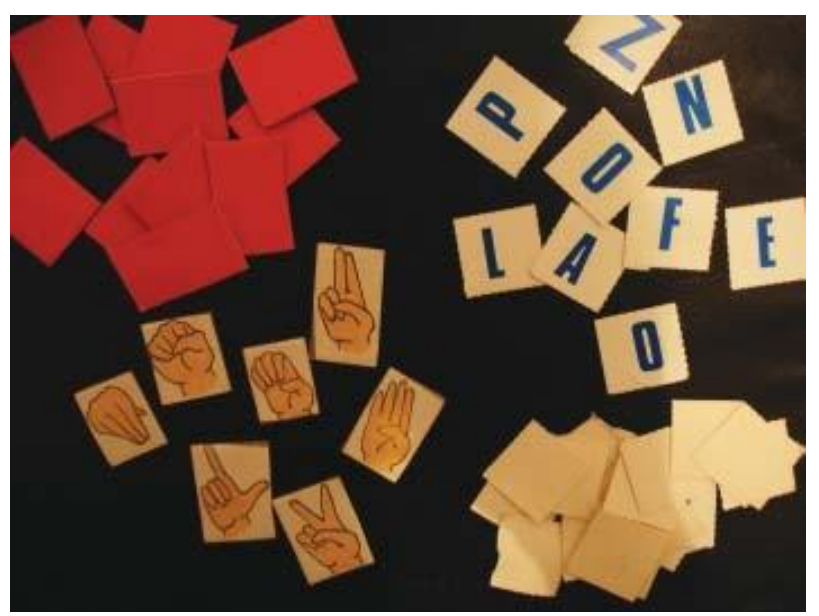

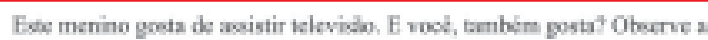
fieura com atencio. Depoés, de respostas somplotas is perzuntas:

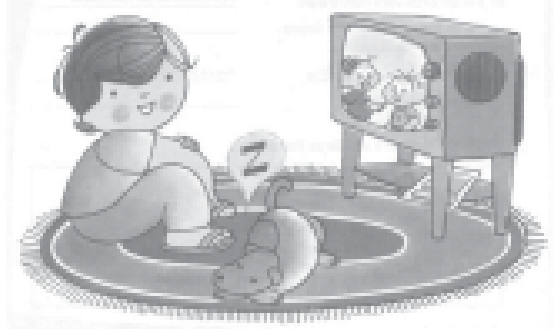

Qual b o nome deste menino?

Oade o mentino sentou?

O que ele lipou?

O que ele edà assistinub?

Quem exti as sec lado?

O quo o animal esta fazendo?

O que vood acha qoe o menino fez depois?

Figura 3 (Produção de partes da história através de desenhos ou colagens) 


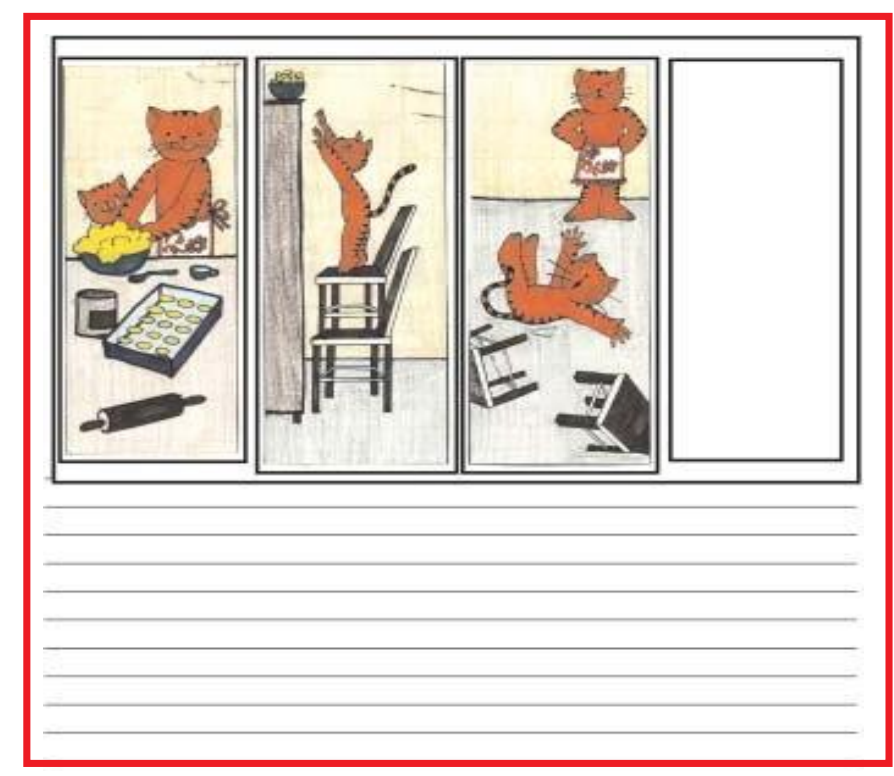

Figura 4 (Bingo)

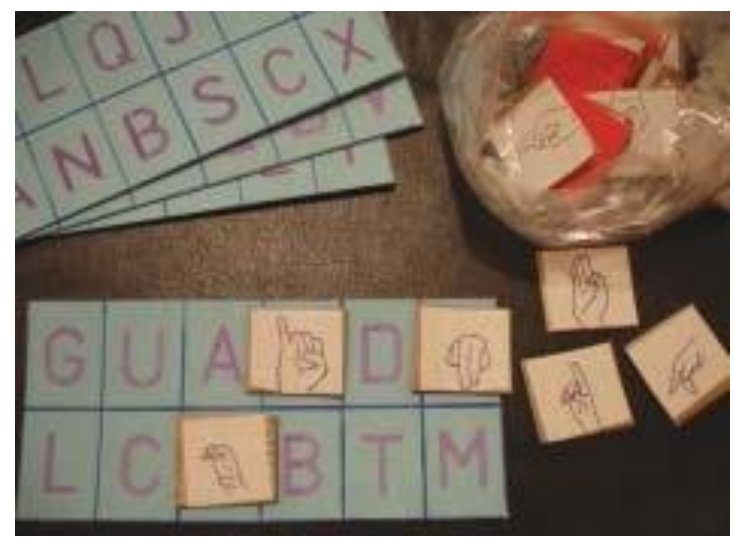

Fonte: Atividades extraídas do livro "Ideias para ensinar português para alunos surdos", da autora Ronice Quadros)

A professora do CAP, além de elaborar várias atividades que planeja de acordo à necessidade de cada aluno, utiliza também a apostila "O surdo...Iniciando a escrita" e o caderno "Atividades pedagógicas para alunos surdos", que aborda o tema Substantivo Próprio e Substantivo Comum (CEADA/ SED/MS).

O material é bem diversificado, apresentando atividades com objetivos e conteúdos variados, o que pode ser observado também no planejamento da professora.

Todo o material é rico em imagens, o que auxilia bastante o surdo na compreensão dos significados. O nível de complexidade das atividades também varia, porém a maior parte é um trabalho inicial para o ensino da Libras e do português, o que imagino ser por conta dos déficits no aprendizado apresentados pelos alunos quando chegam ao AEE. As figuras 5 e 6, abaixo, mostram um pouco do que traz a apostila e as figuras 7, 8, 9 e 10, são propostas do material Atividades pedagógicas para aluno surdo: 
Figura 5 e 6
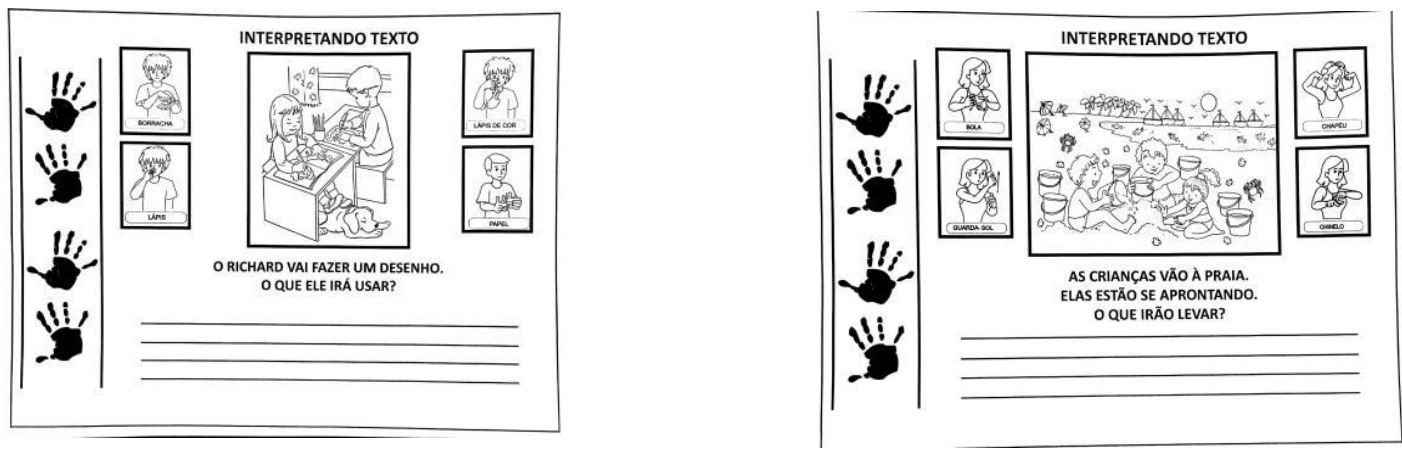

Fonte: Atividades da apostila $\mathrm{O}$ surdo.... Iniciando a escrita.

Figura 7

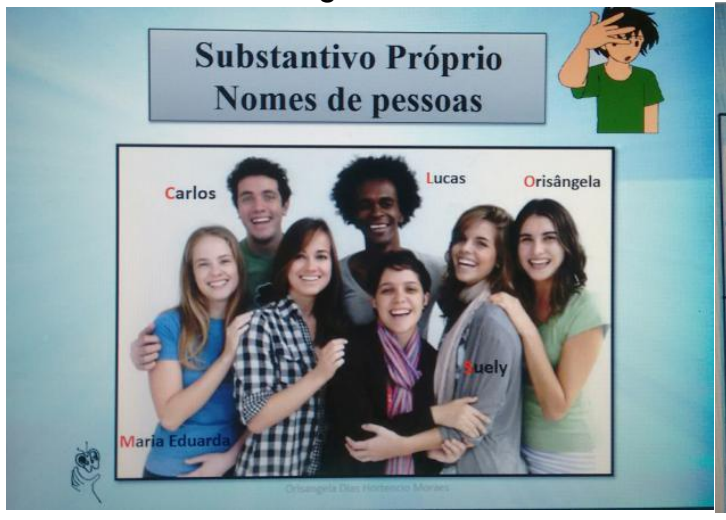

Figura 8

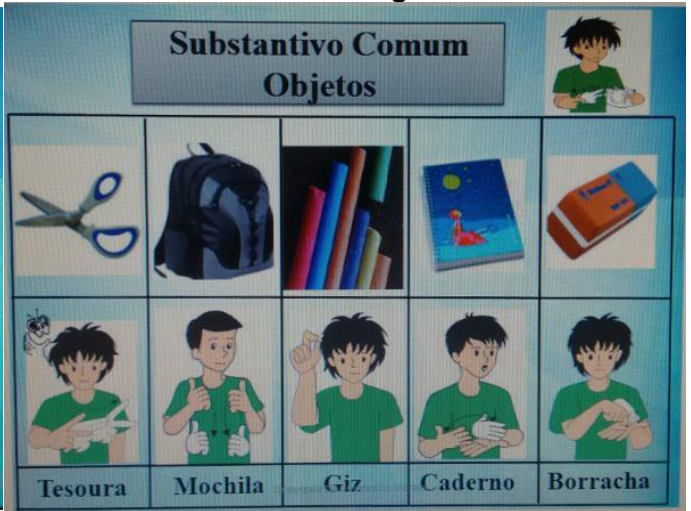

Figura 9

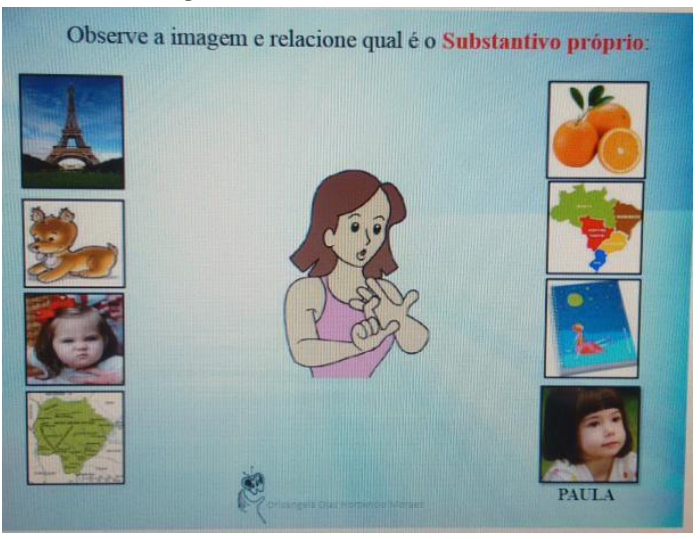

Figura 10

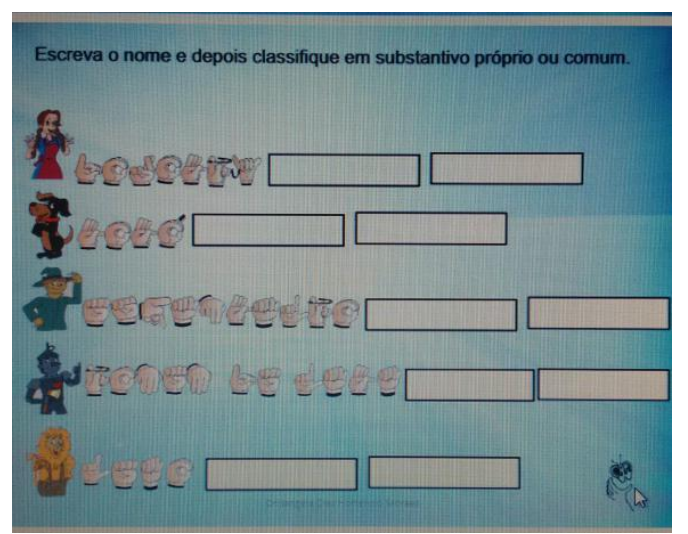

Fonte: Atividades sobre o tema Substantivo próprio e comum extraídas da apostila "Atividades pedagógicas para alunos surdos".

Observou-se também que a docente não utiliza no AEE nenhum tipo de recurso tecnológico ou tecnologia assistiva com seus alunos, apenas 0 computador como recurso para mostrar imagens.

A ludicidade pode ser encontrada nas atividades, pois ela utiliza atividades como caça-palavras, cruzadinhas, jogo da memória, dentre outras, para tornar o aprendizado mais divertido e prazeroso, o que demonstra a 
preocupação e consciência da professora em tornar a aprendizagem significativa através da motivação do seu aluno, como se pode notar nas figuras 11,12 e 13.

Figura 11

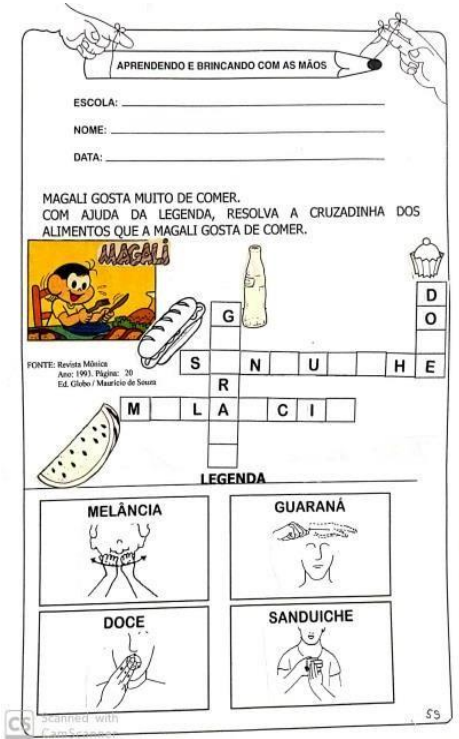

Figura 12

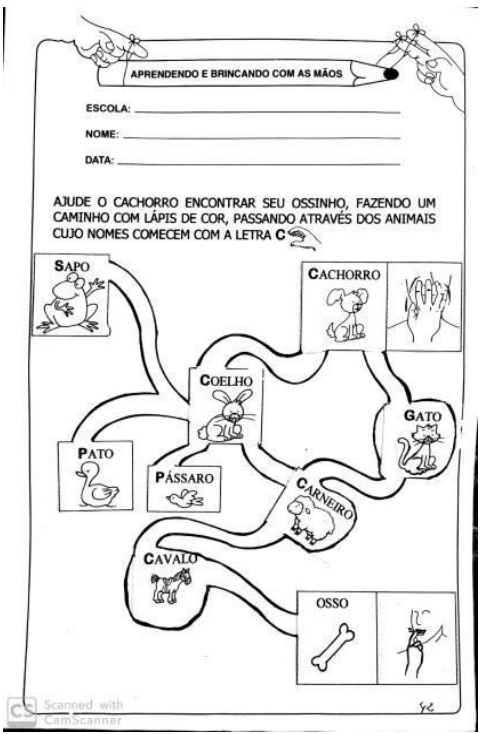

Figura 13

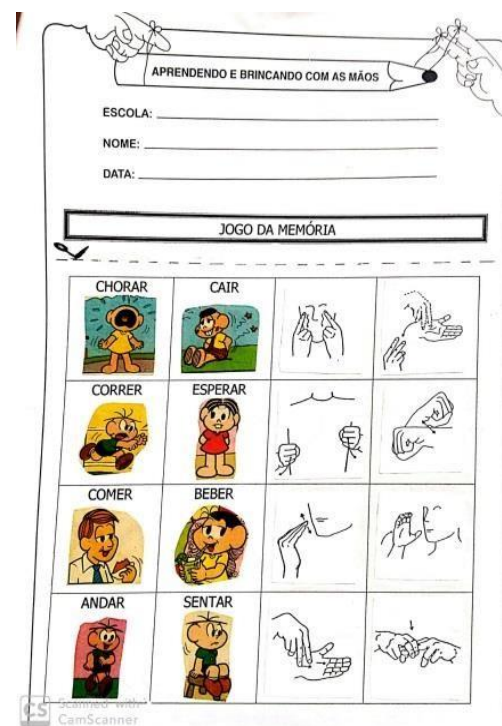

Fonte: Atividades elaboradas pela professora do AEE a partir de pesquisas de imagens na internet

O planejamento feito pela professora é direcionado a cada aluno individualmente, apresentando objetivos comuns entre eles, como a aprendizagem da libras e do português, porém com especificidades já que cada aluno apresenta um nível de aprendizagem e necessidades diferentes. Em seu planejamento a professora descreve os procedimentos para realizar a atividade e em alguns momentos explicita algum objetivo, porém estes não estão descritos em cada planejamento, assim como os conteúdos também não. Porém, pela leitura do plano de aula, pode-se perceber os objetivos e conteúdos implícitos. Percebe-se a preocupação e cuidado da docente em planejar para cada aluno, pensando em como fazê-lo evoluir no aprendizado da libras e do português, interagir mais e diminuir as dificuldades apresentadas na escola. Os aspectos relacionados à afetividade e à ludicidade também perpassam suas atividades e ações, o que pode ser notado em seus planos de aula, como se pode ver na ilustração do seu planejamento, na figura 14: 
Figura 14

Planejamento 08- 07-2019-Gislaine

- Conversar com a aluna perguntar como foi o final de semana (o que fez. O que mais gostou. $O$ que não gostou etc. Porque ajuda a desenvolver o raciocínio.

- Trabalhar com o jogo de memória sobre os gêneros masculino e feminino, encontrar os pares, sinalizando e escrever o nome dos gêneros.

- Reconhecer o nome dos cômodos da casa através de figuras visuais (sala, banheiro, cozinha e quarto) sempre sinalizando e escrevendo no caderno.

- Escrever uma pequena frase usando as palavras estudadas.

Planejamento 09- 07- 2019 - Catiane

- Leitura do livro de história “ A ovelhinha Isolda '. Após a leitura feita pela professora, explorar tudo sobre a leitura (qual personagem que mais gostou; gostou da história; Porque; Inventar um final diferente para a história.

- A professora sinalizará uma frase retirada da história e a aluna escreverá em português- " Sou uma ovelhinha chamada Isolda

- Fazer um ditado sinalizado das palavras tiradas da história (ovelhinha, mamãe, lã, inverno carneiro, grama, pasto, fome, azul e lago).

- Fazer um desenho "A ovelhinha criando um final diferente.
Planejamento 10- 07-2019 - Igor

- Conversar o que fez em casa no final de semana; foi passear; onde; o que mais gostou de fazer.

- Responder a atividade visual sobre palavras, sílabas e letras.

- Apresentar atividade visual digitada: (Decomponha as palavras em silabas e letras de acordo com os desenhos.

- Fazer um desenho com todas as figuras que apareceram na atividade.

- Escolher uma palavra e criar uma frase.

Planejamento 15-07-2019 - Israe

- Reconhecer os substantivos próprios e comuns apresentados na atividade visual.

Carlos- Lucas - José- Salvador - Brasil- São Paulo- Rio de Janeiro Ceará.

Sorvete - abraço- medo - mochila - caderno - borracha - tesoura lápis - livro.

- Observar os desenhos e escrever: próprio ou comum na atividade visual impressa.

- Criar frases com as palavras que aparecem ao lado de cada figura.

AMIGA CELULAR

CARRO ROUPAS

RÁDIO ALICATE

APITO ESCOVA

Fonte: Planejamento elaborado pela professora

Analisando os planos de aula elaborados para cinco dos seus alunos pude identificar alguns conteúdos: gênero masculino e feminino, leitura de palavras, leitura de textos, sinais em libras, interpretação de texto, transcrição da libras para o português escrito, substantivos próprios e comuns e produção textual.

Para trabalhar tais conteúdos ela utiliza atividades como leitura de histórias, ditados sinalizados, pesquisa de letras e palavras em revistas e jornais, cruzadinhas, caça-palavras, jogo da memória, escrita de palavras a partir de sinais em libras e imagens, atividades de completar palavras, encontrar letras do seu nome, dentre outras. Muitas atividades envolvem associação de imagens, escrita das palavras e o sinal correspondente em libras. Ela utiliza também textos de domínio popular ou histórias retiradas da internet para trabalhar interpretação textual.

O trabalho pedagógico também é direcionado através de temas, como pode ser observado em um dos cadernos utilizados pela professora, o qual apresenta atividades retiradas da internet.. As atividades envolvem temas específicos, são eles: números e quantidades, calendário, cores, materiais escolares, frutas, natureza, alimentos, animais aquáticos, verduras e legumes, meios de transporte, fenômenos da natureza e utensílios domésticos. Neste 
material, sempre antes das atividades vem uma leitura com algumas imagens relacionadas ao tema, a escrita da palavra em português e o sinal em libras. Esse tipo de tarefa proporciona a ampliação do vocabulário do aluno tanto em libras como em português, como se pode ver nas figuras 15 e 16:

Figura 15

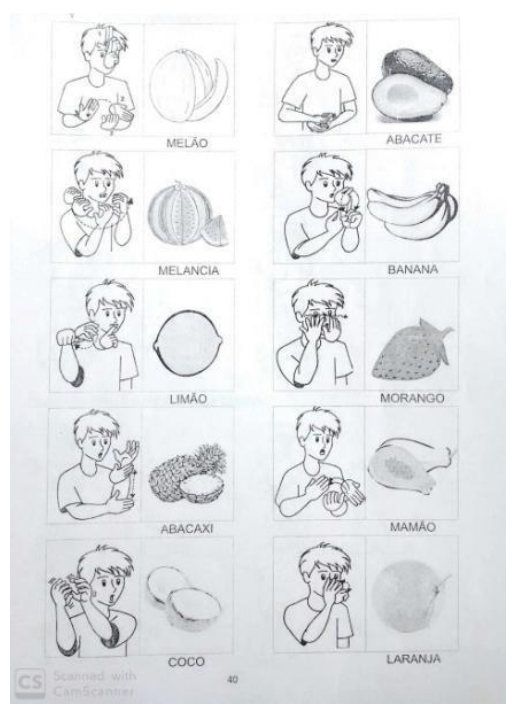

Figura 16

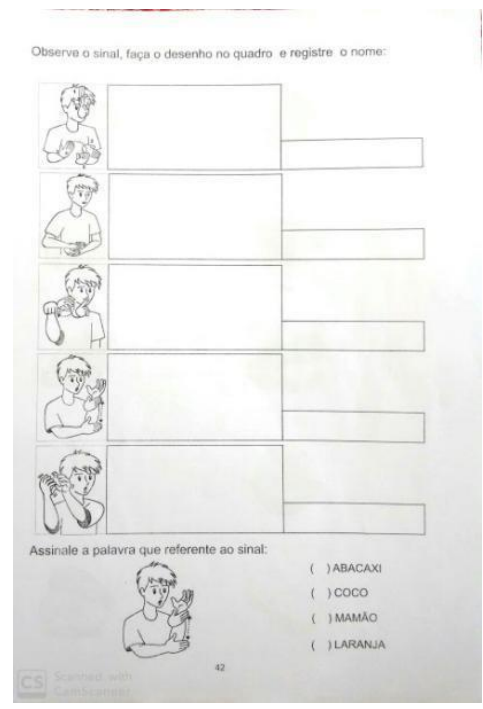

Fonte: Caderno de atividades da professora

Pude notar também uma preocupação da professora em fazer com que o aluno consiga utilizar a escrita percebendo que esta possui uma função social. Uma das atividades é o preenchimento de uma ficha com alguns dados pessoais do aluno, como nome, filiação, números de RG, CPF, endereço, telefone, dados estes muito importantes para todos os indivíduos, surdos e ouvintes.

Ao analisar o material, fiz algumas reflexões. Sabe-se que para o surdo aprender o português depende do estímulo visual e não sonoro como acontece com os ouvintes. Daí a importância das imagens nas atividades. Geralmente, nas atividades de alunos ouvintes, para trabalhar a identificação de objetos iniciados com uma determinada letra, basta colocar as imagens e pedir que identifique quais daquelas imagens tem seus nomes iniciados com determinada letra, porque o ouvinte fala o nome do objeto e associa ao som da letra que está sendo ensinada. Porém, com o surdo é diferente, ele necessita visualizar as imagens e também a escrita das palavras para aprender que aquele objeto inicia com determinada letra, como aparece nas atividades das figuras 17 e 18. 
Figura 17

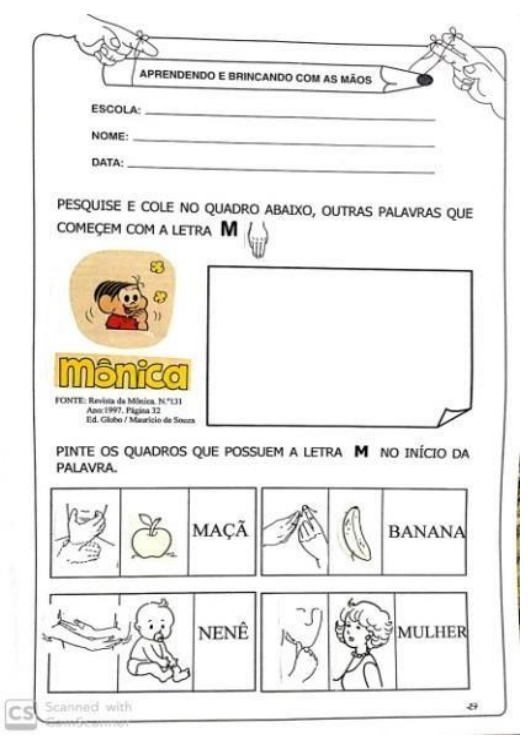

Figura 18

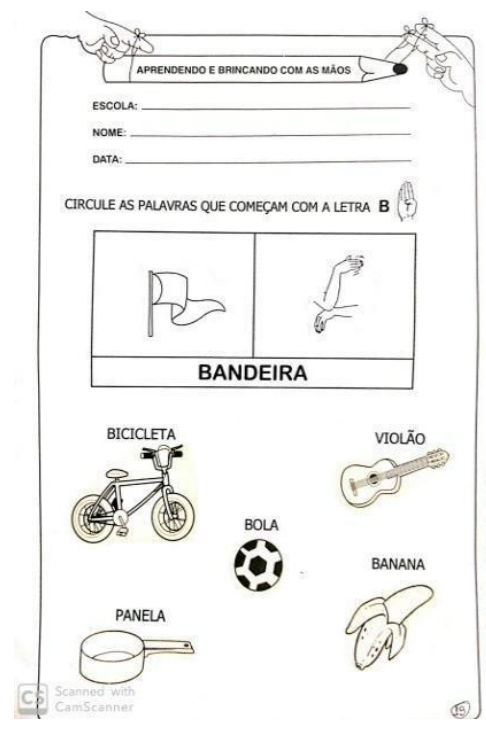

Fonte: Atividades elaboradas pela professora do AEE

Porém, em algumas atividades observei que ao solicitar que o aluno associe a letra ao sinal, a professora coloca também ao lado do sinal a letra novamente, facilitando assim a resposta pelo aluno, como se pode ver na atividade abaixo. O mesmo acontece com as palavras, que aparecem ao lado dos sinais e novamente acima das imagens que representam, como mostram as atividades das figuras 19 e 20 :

Figura 19

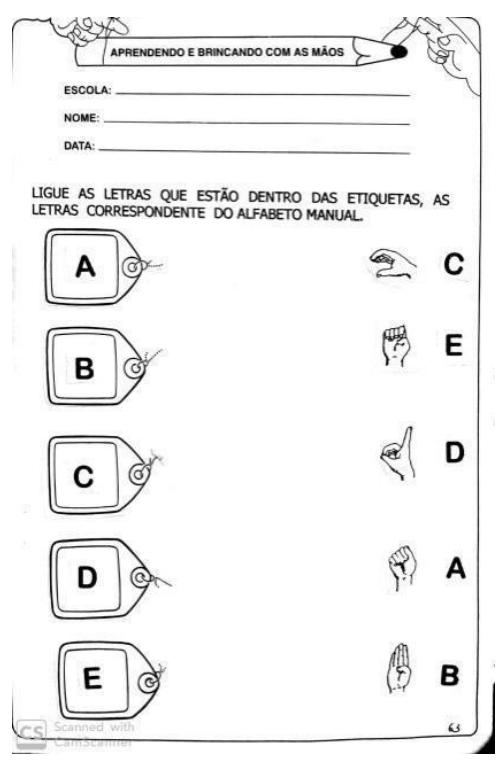

Figura 20

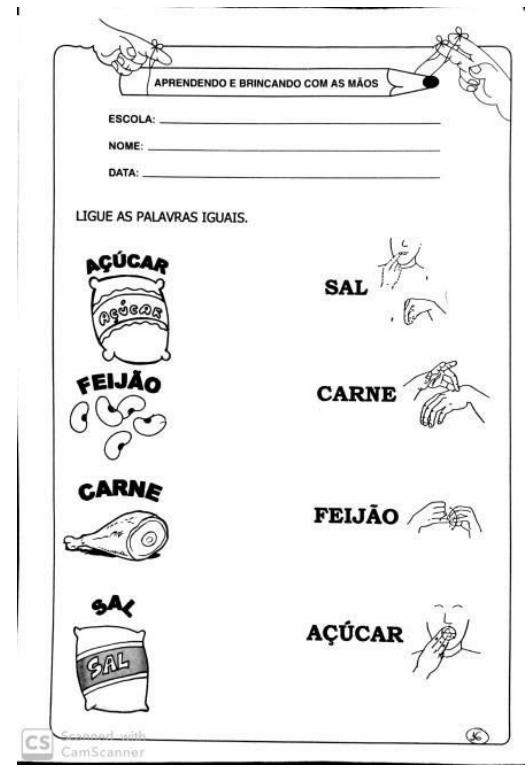

Fonte: Atividades elaboradas pela professora do AEE

Penso que os apoios para o surdo, e especialmente para todos aqueles 
que estão iniciando o aprendizado da escrita em português e da libras, são muito importantes, como podemos notar nas atividades realizadas no CAP, com legendas, imagens, sinais, escrita em português. Porém, penso que em alguns casos o excesso de apoio pode antecipar a resposta do que está sendo solicitado para o aluno.

Com relação ao acompanhamento dos alunos, a professora faz um breve relato sobre cada aluno em seu caderno, registrando quando este iniciou o AEE, o nível de aprendizado, suas necessidades iniciais, algumas características do aluno, dificuldades apresentadas. Além disso, relata como costuma proceder com cada aluno para estimulá-lo e como eles reagem diante de algumas situações. A professora faz um relatório dos avanços conquistados pelos alunos ao final de cada ano.

Um fato que me chamou atenção durante a pesquisa foi saber que apesar da professora planejar suas atividades a partir das necessidades dos seus alunos, não existe nenhum tipo de articulação entre o AEE e o ensino comum. Em conversa informal, a professora afirmou que, geralmente, ela não mantém contato com os professores da rede regular de ensino que tem alunos atendidos neste Centro. A Política de Educação Especial na Perspectiva da Educação Inclusiva deixa claro que o trabalho pedagógico do AEE deve manter articulação com o ensino comum, se possível com espaços de atendimento especializado dentro da própria escola.

Tomando como referência o Decreto ํㅜ 7.611/2011, que coloca como um dos objetivos do AEE garantir serviços de apoio especializado de acordo com as necessidades individuais dos estudantes, penso que a professora atende bem essa normativa, pois ela planeja observando as necessidades e níveis de aprendizagem de cada aluno.

Quanto a outro objetivo posto no decreto, que é fomentar o desenvolvimento de recursos didáticos e pedagógicos que eliminem as barreiras no processo de ensino e aprendizagem, verifiquei que há uma variedade de materiais e atividades que buscam justamente eliminar as barreiras comunicativas impostas pela surdez e pela maneira excludente que a maioria das escolas lidam com o aluno surdo.

Um outro fator positivo do AEE é a possibilidade de convivência do surdo com seus pares, que é uma recomendação da Política de Educação Especial. Muitas vezes, a criança surda não convive com nenhum outro surdo na família e nem na escola, o que é muito prejudicial para a formação da sua identidade, para a construção da sua autoestima e também para 0 aprendizado da sua primeira língua, que é a libras. No CAP, além de poder ter contato com outras crianças e adultos surdos, a sua professora também é surda, possibilitando ao sujeito sentir-se mais integrado em seu meio.

\section{CONSIDERAÇÕES FINAIS}

Tendo como principal documento norteador deste trabalho a Política de Educação Especial na Perspectiva da Educação Inclusiva, após a pesquisa em uma sala de AEE do Centro de Apoio Pedagógico - CAP, pode-se inferir que o Atendimento Educacional Especializado para o aluno surdo é de fundamental importância, pois ele tenta incluir, integrar o sujeito surdo na sociedade, diminuindo as barreiras linguísticas ou comunicacionais que thes 
são apresentadas. Vale destacar que não é a surdez em si que cria estas barreiras, mas sim a falta de informação e formação da sociedade de modo geral e, mais especificamente, dos profissionais da educação para lidar com as especificidades desses sujeitos.

O ensino regular ainda deixa muitas lacunas no aprendizado dos estudantes surdos, pois não há intérpretes na escolas, ou há intérpretes com pouca formação, os professores não sabem libras, muitas vezes não há nas escolas sala de recursos ou outro espaço de atendimento especializado, ficando o aluno surdo à margem, sem compreender ou ser compreendido.

A pesquisa mostrou que apesar de não haver uma articulação direta entre a professora do AEE no CAP e os professores das escolas comuns que tem alunos atendidos nesta Instituição, existe um trabalho pedagógico elaborado a partir das necessidades apresentadas pelos alunos que buscam o Atendimento Educacional Especializado. O planejamento é individualizado e traça objetivos pontuais para cada um, o que é muito bom.

Pode-se ver através da análise das atividades e dos planos de aula que as ações pedagógicas são direcionadas ao ensino da libras e do português, já que a barreira comunicativa gerada pela dificuldade com as duas línguas, a libras como língua materna dos surdos, e a língua Portuguesa escrita, que tem um papel social importante na vida de todos indivíduos, leva a problemas na aprendizagem. Todas as atividades pensadas para cada aluno individualmente tem por objetivo principal fazê-lo comunicar-se melhor, através da sinalização ou da escrita, podendo interagir com seus pares e também com o mundo ouvinte. Este com suas limitações já que muitos desconhecem a Língua de sinais.

As ações pedagógicas realizadas pela professora no AEE são um trabalho comprometido, fundamentado em um bom referencial teórico, diversificado, lúdico, atrelado a uma função social que permeia o aprendizado das duas línguas, a libras e o português.

\section{REFERÊNCIAS}

ALBUQUERQUE, Ednea Rodrigues de. Prática pedagógica inclusiva: um estudo de caso em escola com atendimento educacional especializado (AEE) em Jaboatão dos Guararapes-PE. 2014. 340 f. Tese de doutorado Universidade Federal de Pernambuco. Disponível em: http://bdtd.ibict.br, acesso em 28/03/2019.

BRASIL. Política Nacional de Educação Especial na Perspectiva da Educação Inclusiva. Brasília:MEC/SEESP, 2008. Disponível em: www.portal.mec.gov.br. Acesso em 08/03/2019.

BRASIL. MEC/ SEESP. Presidência da República. Decreto n. 7611, de 17 de novembro de 2011. Dispõe sobre a Educação Especial, o atendimento educacional especializado e dá outras providências. Brasília: 2011. Disponível em: http://portal.mec.gov..br. Acesso em 08/03/2019.

DAMÁZIO, Mirlene Ferreira Macedo. Atendimento Educacional Especializado: pessoa com surdez. SEESP, SEED, MEC: Brasília: 2007. 
FERREIRA, Cleonice Bicudo da Rocha. Atendimento educacional especializado para pessoas com surdez. 2011. 66 f. Monografia da Especialização em Desenvolvimento Humano, Educação e Inclusão Escolar Universidade de Brasília, Universidade Aberta do Brasil. Disponível em: http://bdm.unb.br/handle/10483/3333. Acesso em 06/07/2019.

SILVEIRA, Denise Tolfo; CÓRDOVA, Fernanda Peixoto. A Pesquisa científica. In: GERHARDT, Tatiana Engel; SILVEIRA, Denise Tolfo (orgs). Métodos de pesquisa. Porto Alegre: Editora UFRGS, 2009.

KASSAR, M; RABELO, A.S. O "especial" na educação, o atendimento especializado e a educação especial. In: SEMINÁRIO NACIONAL DE PESQUISA EM EDUCAÇÃO ESPECIAL: PRÁTICA PEDAGÓGICA NA EDUCAÇÃO ESPECIAL: Multiplicidade do atendimento educacional especializado, 6, 2011, Nova Almeida. Anais...Nova Almeida: EDUFES, 2011.

MINAYO, Maria Cecília de Souza (Org.). Pesquisa Social: Teoria, Método e Criativiadade. Petrópolis - RJ: Vozes, 1994.

QUADROS, Ronice Müller de. Idéias para ensinar português para alunos surdos.

Brasília : MEC, SEESP, 2006.

SANTOS, David Kaique Rodrigues dos; SANTANA, Neemias Gomes. A formação do professor para a educação de surdos. In: MACEDO, Yuri Miguel; SANTOS, David Kaique Rodrigues dos; MAIA, Cláudia Braga (orgs.). Inclusão e Diversidade na Educação: desafios e possibilidades. Porto Seguro: Editora Oyá, 2019. 